\title{
Factors Affecting Timing of Breeding in the Tawny Owl Strix aluco
}

\author{
Tapio Solonen ${ }^{*}$
}

\author{
Luontotutkimus Solonen Oy, Neitsytsaarentie 7 b B 147, FI-00960 Helsinki, Finland
}

\begin{abstract}
Relevant variables characterising factors suspected to affect timing of breeding in birds may be difficult to measure. Then, easily available proxies, i.e. variables that are expected to vary consistently with some affecting factors, may be used instead. In the present study on tawny owls, I used besides individual characteristics of parent birds both detailed measurements of the prey base of territories, local and general indices of vole abundance as well as local and general weather conditions as explanatory variables. Owls tended to breed the earlier the older and the heavier they were. Breeding was the earlier the higher the abundance of water voles and the proportion of field voles in the territorial prey samples. Owls bred earlier when the local abundance of small voles in the preceding autumn was high. Regional vole indices showed no associations with timing of owls' breeding. Single winter weather variables did not show any significant associations neither. In combination with the advancing effect of water vole abundance, however, the delaying effect of the depth of the snow cover in March was significant. Models based on different data sets showed different kinds of associations between the abundance of small voles and timing of breeding in owls. The best models in which both intrinsic and extrinsic explanatory variables (characteristics of parent birds and environmental factors, respectively) were included did not differ considerably from each other. The occurrence of water voles in prey samples governed the best models. The results suggest, that without detailed knowledge on the prey base of territory, misleading results may emerge and the importance of small voles in governing breeding of owls may be overemphasised.
\end{abstract}

Keywords: Extrinsic factors, fixed effects, intrinsic factors, local prey, random effects, regional vole indices, winter weather variables.

\section{INTRODUCTION}

The onset of breeding in birds is governed by various intrinsic and extrinsic factors, including individual characteristics of parent birds and prevailing environmental conditions, in particular food supply, respectively [1-4]. The early onset of breeding has been suggested as a favourable trait that evolved to ensure the best feeding conditions for the forthcoming young [e.g. 1]. In various long-lived species of northern latitudes early breeding is important to ensure that the time-consuming reproduction process can be conducted within the strict limits of tolerable environmental conditions and for young birds to successfully reach independence [57]. Early breeding may also offer the opportunity to produce more clutches and young within a season [e.g. 2].

Determining timing of breeding on the basis of direct observations during the egg laying is a relatively easy task if there is no risk of desertion of the clutch. Particularly convenient it is on the basis of age of nestlings if it can be determined by some measurement of growth. Measuring meaningful variables characterising intrinsic and extrinsic factors suspected to affect timing of breeding may, however, be more complicated, and this may restrict the sample size available. For instance, detailed observation and measurement of individual characteristics of parent birds requires live-catching of birds that may be impractical or difficult to conduct. Relevant characteristics of territory, including the

*Address correspondence to this author at the Luontotutkimus Solonen Oy, Neitsytsaarentie 7b B 147, FI-00960 Helsinki, Finland;

Tel: +358-41- 4602101; E-mail: tapio.solonen@pp.inet.fi prey base during the pre-laying period may be very laborious to determine with the precision needed. In such cases, more easily available indirect measurements may be used as proxies, i.e. as variables that are expected to vary consistently with some affecting factors. Their capability to predict the effects considered, however, vary and may be quite restricted.

In the present study, I examined the role of some intrinsic and extrinsic factors in timing of breeding in the tawny owl Strix aluco (Linnaeus 1758) in southern Finland. This species has an advantage to allow gathering various kinds of relevant data with relative ease. For instance, artificial nest sites of the species are easily accessible, breeding adults are quite easy to catch from nests, and prey used can be analysed from the remains in the nest bottom litter samples [e.g. 810]. So, in addition to general indices of food abundance and weather conditions, I also used individual characteristics of parent birds and detailed measurements of territorial prey base as explanatory variables. My aim was not only to evaluate some expectations of associations between variables but also to demonstrate effects of sample size, different data sets, and various proxies of explanatory variables on the results and conclusions derived.

My expectations were as follows (Fig. 1): 1) Being more competent in reproduction [9], older individuals might also be more competent being capable to breed earlier than younger ones [e.g. 11, 12]. Birds that are smaller-sized [13, 14] but heavier, and thus probably in better condition [15, 16], should breed earlier than larger but lighter ones. 2) High prevalence of voles (peaks of vole cycles, good availability 
Intrinsic factors

$\begin{array}{lll} & \text { Female quality } & \text { Male quality } \\ \text { Timing of breeding } & <\text { Female body condition }<\text { Male body condition } \\ & \\ & << \\ & <\text { Female age } & \text { Male age } \wedge \\ <\text { Female size } & \text { Male size } \wedge\end{array}$

\section{Extrinsic factors}

$\begin{array}{ll}\text { Food factors } & \text { Weather factors } \\ <\underset{\wedge}{\text { Food supply }} & \\ \text { Prey abundance } & <\text { Temperature } \\ <\text { Prey availability } \wedge & <\text { Snow cover }\end{array}$

Fig. (1). A conceptual model for the links between different factors expected to affect the timing of breeding in the tawny owl Strix aluco in southern Finland.

due to minor snow) and rats (permanent local food source) in the prey base of territory should be associated with early breeding, corresponding to their relationship with reproduction [8]. Abundance of water voles Arvicola amphibius (Linnaeus 1758) should be important particularly in combination with minor snow cover $[8,10]$. 3) High general abundance of small voles and mild and less snowy conditions of the preceding winter should have an advancing effect on breeding of owls [e.g. 2, 17]. Compared to territorial and individual variables, however, the explanatory power of regional vole indices and general weather variables may be rather weak and insignificant, particularly in small samples.

\section{MATERIAL AND METHODS}

The tawny owl is a widespread bird of prey of rural and urban habitats in Europe [18, 19]. It commonly occupies habitats in the vicinity of human settlements. A suitable nesting cavity is an essential prerequisite for the tawny owl's breeding, which is otherwise largely governed by adequate availability of food [e.g. 8, 10, 20]. In the North, the availability of food for breeding tawny owls seems to be particularly affected by the pronounced and more or less cyclic fluctuations of vole populations [21-24] and it is modified by habitat $[25,26]$ and various climatic factors $[8,20,22,27$, $28]$.

\section{Population Study and Study Area}

The present data were derived from a ten-year period (between 1989 and 1999) of a long-term study on population dynamics of the tawny owl conducted in Uusimaa $\left(60^{\circ} \mathrm{N}\right.$, $25^{\circ} \mathrm{E}$ ), near the southern coast of Finland [8]. The study area of more than $500 \mathrm{~km}^{2}$ consisted of low-lying rural habitats of mixed fields and forests, as well as more urban environments of the capital Helsinki and its surroundings. Tawny owls occupied the study area in a relatively even manner, following the availability of suitable nest sites, mainly nest boxes erected throughout the study area. The hatching success of birds was recorded for each year of the study. Only the successfully hatched clutches were included in the present data because the timing of breeding was determined on the basis of the hatching date.

\section{Determination of the Hatching Date}

In order to estimate the hatching dates, I measured the wing length of nestlings from 193 broods using the maxi- mum method [e.g. 29]. I estimated the age of the oldest young using Jokinen's [30] wing growth curve. The hatching dates were estimated from the age of the young. For the timing of egg laying, I used an incubation time of 28 days [19]. Calendar days were converted to Julian days, starting from the first day of January.

\section{Explanatory Variables}

\section{Intrinsic Factors}

Breeding tawny owls (females and males) of the population were captured at nests by hoop net or trap around the middle of the nestling period. Due to the well-known risk of desertion of nest in the early phases of breeding in the tawny owl [9], catchings were not performed earlier. Captures occurred mainly in May, but were distributed from March to June. Each individual was captured only once during each breeding season. The total data included 193 breeding pairs.

Birds were sexed on the basis of their size, wing length, body mass and the prominent incubation patch of the females $[9,20,31]$. I determined the age of birds by the plumage patterns [32]. The three age categories used included $1 \mathrm{yr}$ old, 2 yrs old, and 3 yrs old or older birds. The maximum wing length, i.e., the distance between the carpal joint and the tip of the longest primary [29], indicated the size of an individual. The body mass (measured by Pesola spring balance to the nearest gram) was used as a measure of body condition [33]. Within sex, the explanatory variables were usually correlated. The annual values of male and female body mass were also significantly correlated $(r=0.417, d f=$ $87, P<0.001)$.

\section{Food Variables}

Local prey of tawny owls during the breeding season was studied by analysing 51 nest bottom litter samples collected after breeding from 30 different locations (local nesting territories) [34]. The samples represented both good (33) and poor (18) vole years. Food remains (bones, feathers etc.) were separated from the litter by picking with tweezers. They were assorted and identified in appropriate categories [8]. In each prey category, the number of individuals was counted on the basis of the most common individual bones found. The identification of mammals was based mainly on jawbones (mandibles) and bones of limbs, including hipbones, femurs, tibiae, and humeri. Birds were recognised based on limb-bones (femurs, tibio-tarsi, tarso-metatarsi, 
humeri, ulnae, metacarpals) as well as sternums, beaks, and feathers. The numbers and proportions of different species of voles in samples were significantly correlated $(P<0.05)$.

The species of small voles that were considered to form an important food source for owls and the abundance of which was estimated on the basis of local and regional snaptrappings were the bank vole Myodes glareolus (Schreber 1780) and the field vole Microtus agrestis (Linnaeus 1761). The catch indices were expressed as individuals per 100 trapnights. General fluctuations of the vole populations within the study area were monitored by small-scale trapping, catch indices of which are here called "local vole indices". In a central locality (Sipoo, Hindsby), small mammals were trapped in each autumn (October-November) and spring (May) at 30 standard points along a line of about $1.5 \mathrm{~km}$ with three snap-traps at each point (total of 90 traps) throughout a 24-hour period. On the basis of the vole index of the preceding autumn, the study years of the breeding seasons were classified as "good" or "poor" ones, corresponding to good and poor vole years in the three-year vole cycles. From the point of view of tawny owls, the habitat distribution of the trapping line might have been concentrated in forests, but old fields were also included. However, the proportions of forest and open habitat seemed roughly to correspond to those of the district at large.

In order to characterise the general abundance of food for owls before breeding season, I used regional small vole indices of the preceding autumn and current spring. Each index was based on a total of 384 trap-nights of trappings conducted during two-day periods in early October and May in two localities near the present study area and they included both forest and old field habitats, 192 trap-nights each [Kimpari Bird Projects, 24, 35]. These indices seemed to characterise fluctuations in the abundance of voles over a larger area in southern Finland relatively well $[22,24]$.

\section{Weather Variables}

I examined effects of the local mean temperature of winter, including January, February and March, as well as the depth of the snow cover in the middle of March (Finnish Meteorological Institute). These variables seemed to characterise well the strength of winter before the breeding season of tawny owls. For characterising the weather conditions at large, I applied the winter index of the North Atlantic oscillation (NAO), which is the most prominent pattern of atmospheric variability over the northern hemisphere and which has a marked effect on European weather conditions [36, 37]. The increasing positive values of the winter NAO indices, averaging the monthly values from December to March (http://www.cru.uea.ac.uk/cru/data/nao.htm [accessed 23 March 2011]), indicate milder and wetter winter weathers in Europe.

Preliminary examination of the data showed that there was a significant negative correlation between the mean winter temperature and the depth of the snow cover in March $(r=-0.664, d f=9, P=0.013)$. There was a significant positive correlation between the winter NAO index and local mean temperature of winter $(r=0.744, d f=9, P=0.004)$ whereas the relationship between the winter NAO index and the depth of the snow cover in March was only nearly significant $(r=-0.485, d f=9, P<0.065)$.

\section{Data Sets Used}

The material used consisted of three smaller sets of data on tawny owls: 1) nestings from which both the hatching date was determined and each parent bird was caught and examined $(\mathrm{N}=89), 2)$ nestings from which both the hatching date was determined and prey remains were analysed $(\mathrm{N}=$ 42), and 3) nestings from which the hatching date was determined, each parent bird was caught and examined, and prey remains were analysed $(\mathrm{N}=21)$. Thus, in different analyses, the numbers and combination of variables somewhat varied.

\section{Statistics}

In searching for the factors affecting timing of breeding in the tawny owl, I used linear mixed effects models (lme) [38] from nlme in $\mathrm{R}$ statistical package [39, 40]. In the analyses, I used the Julian hatching date of the oldest young in the brood as the response variable. The explanatory variables (fixed effects) included the age, wing length and body mass of the parent birds (intrinsic factors) as well as various food and weather indices (extrinsic factors). The territorial food indices included the numbers or proportions of small voles (field voles and bank voles both separately and combined), water voles, rats, mice, shrews, and birds in the prey remains of the nest bottom litter samples. In separate models, local and regional autumn and spring vole indices based on snap-trappings of small voles were used. Weather variables included the mean temperature of the preceding winter, depth of the snow cover in March and the winter NAO index. Due to the common correlation between variables, largely only separate effects of variables were considered. The territory ID, indicating unknown local impacts, and year, indicating annually varying unknown factors, characterised random effects. The models used had a general appearance as follows: Hatching date model <- lme (Hatching date $\sim$ Fixed effects, Random effects $\sim$ Territory ID * Year). The fixed effects were fit into the model as single variables or in reasonable combinations of variables, following the expectations issued (Fig. 1). The significance of variables in each model was examined and the models were ranked on the basis of the Akaike Information Criterion (AIC) [41, 42].

\section{RESULTS}

Older birds tended to breed earlier than younger ones (Table 1). This concerned particularly females. Large body size was associated with early breeding in females but not in males. Birds that were heavy and in good body condition bred earlier than lighter and less fit individuals. The combining of male and female chracteristics did not make the models better.

The breeding of owls was the earlier, the higher the number of water voles and the proportion of field voles in the territorial prey samples (Table 2). The occurrence of rats showed no such association. The proportion of shrews was higher in the prey samples of late nestings.

Owls bred earlier when the local vole levels in the preceding autumn were high (Table 3 ). There were no significant associations between the regional vole indices and timing of breeding of owls. 
Table 1. Fixed Effects of Age, Size (Wing Length) and Condition (Body Mass) of Parent Birds on Timing of Breeding in the Tawny Owl Strix aluco in Southern Finland Based on Linear Mixed Effects Models (Hatching Date Factor, Random Effects [Territory ID, Year]). The Values of Effects, Standard Errors (SE), Degrees of Freedom (df), Test Statistics (t), Probabilities (p) and Akaike's Information Criterions (AIC) Are Given. In Each Model, the Number of Observations Is 89 and Number of Groups (Years) 10. Negative Relationships Suggest Advancing Effects



Winter weather variables, in general, showed at their best only nearly significant associations with the timing of owls' breeding (Table 4). In combination with the advancing effect of water vole abundance, however, the delaying effect of the depth of the snow cover in March was significant. Nevertheless, the addition of the snow cover did not make the model better (AIC 322.795 > 321.290).

Models based on different data sets showed different kinds of associations between the abundance of small voles and timing of breeding in tawny owls (Table 5). Significant associations emerged particularly in the smallest data sets of various prey samples. In a larger data set, the local vole indices of the preceding autumn also showed a significant relationship with the hatching date of owls while none of the regional vole indices showed such an association.

The best models in which both intrinsic and extrinsic explanatory variables were included did not differ considerably from each other (AICs were relatively similar) (Table 6). The only significant factor, the occurrence of water voles in the prey remains of the nest bottom litter samples, governed the best models. In addition, male body mass and the winter NAO index were included in several of the best models.

\section{DISCUSSION}

In the mixed effects models constructed, the prevalence of water voles in the local prey base seemed to be the most important single factor affecting timing of breeding in the tawny owl population studied. Occurrence of smaller-sized species of voles also seemed to be of considerable importance. Detection of these associations seemed to depend largely on the capability of the proxies used as explanatory variables to characterise the underlying factors.

\section{Intrinsic Factors}

As expected, older birds, in particular females, tended to breed earlier than younger ones. This seemed to be a common phenomenon in birds $[11,12]$ but not a universal one even in the tawny owl [see 7]. Large body size in earlybreeding females was against some earlier findings [e.g. 13, 14]. High body mass, indicating good body condition, was a good indicator of early breeding in both sexes. This is suggested particularly for female birds also in various earlier studies [15, 16, 43].

\section{Local Prey Base}

The prey samples representing single local territories showed clearly the importance of the occurrence of voles, in particular water voles, in timing of breeding in the tawny owl population studied. High prevalence of voles, suggesting peak years in the vole cycles or good availability of voles due to minor snow cover, seem to be a common prerequisite for early breeding in owls [e.g. 2, 10].

Occurrence of rats in the prey base of territories did not show the expected advance in breeding in the present data. This might be due to an uneven distribution of rat concentrations of the study area and the small number of nest samples analysed. High proportion of shrews in late nests refers rather to lack of voles than to some direct effect of shrews in owls' diet.

\section{Fluctuations in Vole Abundance}

Abundance fluctuations of small voles did not only reflect in the prey base of territories but also in the local and regional vole catch indices. The association between the regional indices and timing of breeding in the tawny owl 
Table 2. Associations Between the Indices of Single Species or Categories of Territorial Prey Base (Abundance [A] and Proportion [\%] of Individuals of Prey Categories in Remains Identified from the Nest Bottom Litter Samples) and Timing of Breeding (Julian Hatching Date of the Oldest Young in the Brood) in the Tawny Owl Strix aluco in Linear Mixed Effects Models (Hatching Date Prey Index, Random Effects [Territory ID, Year]). The Values of Effects, Standard Errors (SE), Degrees of Freedom (df), Test Statistics (t), Probabilities (p) and Akaike's Information Criterions (AIC) Are Given. In Each Model, the Number of Observations Is 42 and Number of Groups (Years) 10. Negative Relationships Suggest Advancing Effects

\begin{tabular}{|c|c|c|c|c|c|c|}
\hline (Intercept) & 120.799 & 3.154 & 31 & 38.301 & $<0.001$ & 328.747 \\
\hline Field voles A & -0.267 & 0.162 & 31 & -1.647 & 0.110 & \\
\hline (Intercept) & 119.447 & 3.576 & 31 & 33.404 & $<0.001$ & 328.516 \\
\hline (Intercept) & 120.757 & 3.263 & 31 & 37.006 & $<0.001$ & 329.688 \\
\hline Small voles A & -0.191 & 0.132 & 31 & -1.454 & 0.156 & \\
\hline (Intercept) & 123.070 & 2.910 & 31 & 42.294 & $<0.001$ & 322.795 \\
\hline Water voles A & -0.768 & 0.255 & 31 & -3.010 & 0.005 & \\
\hline (Intercept) & 116.609 & 3.821 & 31 & 30.517 & $<0.001$ & 328.798 \\
\hline Mice A & 0.314 & 0.332 & 31 & 0.947 & 0.351 & \\
\hline (Intercept) & 117.468 & 3.405 & 31 & 34.495 & $<0.001$ & 329.437 \\
\hline Shrews A & 0.226 & 0.217 & 31 & 1.043 & 0.305 & \\
\hline (Intercept) & 117.074 & 4.030 & 31 & 29.050 & $<0.001$ & 330.034 \\
\hline Birds A & 0.148 & 0.224 & 31 & 0.662 & 0.513 & \\
\hline (Intercept) & 124.827 & 3.383 & 31 & 36.901 & $<0.001$ & 325.261 \\
\hline (Intercept) & 127.344 & 2.581 & 31 & 49.337 & $<0.001$ & 312.443 \\
\hline Water voles \% & -0.917 & 0.176 & 31 & -5.220 & $<0.001$ & \\
\hline (Intercept) & 119.269 & 3.729 & 31 & 31.988 & $<0.001$ & 328.207 \\
\hline Rats \% & -0.203 & 0.661 & 31 & -0.306 & 0.761 & \\
\hline (Intercept) & 114.637 & 3.933 & 31 & 29.146 & $<0.001$ & 328.204 \\
\hline Mice $\%$ & 0.327 & 0.206 & 31 & 1.585 & 0.123 & \\
\hline (Intercept) & 114.513 & 3.536 & 31 & 32.381 & $<0.001$ & 324.359 \\
\hline Shrews \% & 0.551 & 0.216 & 31 & 2.554 & 0.016 & \\
\hline (Intercept) & 113.718 & 4.171 & 31 & 27.264 & $<0.001$ & 328.544 \\
\hline Birds \% & 0.222 & 0.125 & 31 & 1.773 & 0.086 & \\
\hline
\end{tabular}


Table 3. Associations Between the Indices of Local and Regional Autumn and Spring Abundance of Small Voles (Microtus, Myodes) and Timing of Breeding (Julian Hatching Date of the Oldest Young in the Brood) in the Tawny Owl Strix aluco in Linear Mixed Effects Models (Hatching Date Vole Index, Random Effects [Territory ID, Year]). The 'Mean' Indices Are Averages Between Autumn and Spring. The Values of Effects, Standard Errors (SE), Degrees of Freedom (df), Test Statistics (t), Probabilities (p) and Akaike's Information Criterions (AIC) Are Given. In Each Model, the Number of Observations is 89 and Number of Groups (Years) 10. Negative Relationships Suggest Advancing Effects

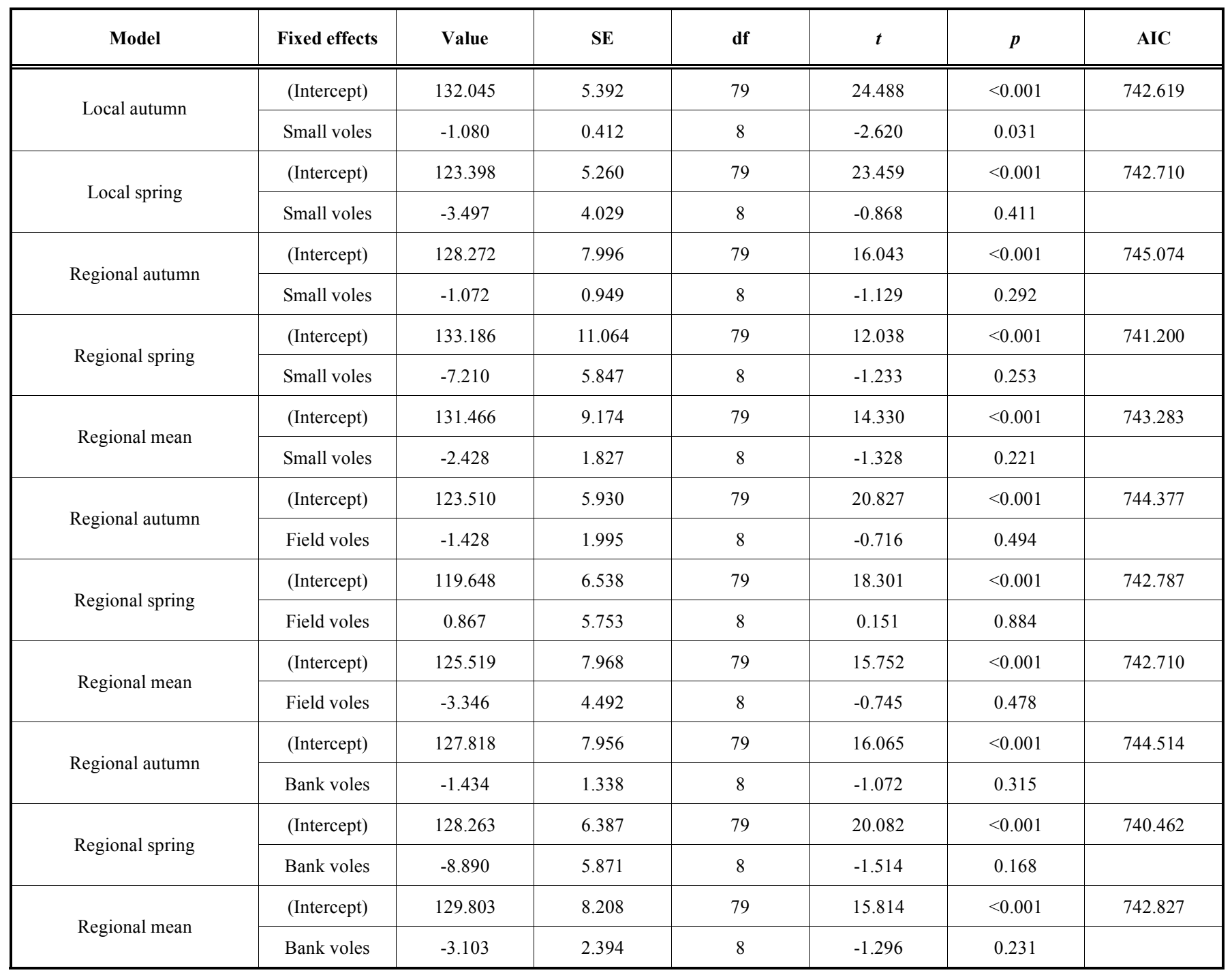

population studied was, however, not significant [cf. also $10]$. For a larger data set and a longer period of time, however, a significant association emerged [17]. This suggests that there is considerable spatial and temporal variation in the general pattern of vole cycles, in spite of the fact that the cycles may be in a similar general phase over a large spatial scale $[23,27,44]$.

\section{Winter Weather}

In general, the effects of winter weather on timing of breeding in owls seemed to be minor. In any case, these effects should be largely indirect [22, 24]. This is suggested also by the relationships between the snow cover, occurrence of water voles, and hatching date of owls in the present study. Correspondingly, the finding that birds that were heavy and in good body condition bred earlier than other individuals suggests that winter weather conditions may be involved by affecting the availability of small voles that, in turn, could be responsible for good body condition of overwintering owls. However, the adding of snow cover along with a measure of water vole occurrence into the model seems not make it better.

\section{Effects of Quality and Quantity of Data}

For practical reasons, I generally used various indirect measures as proxies of variables in the mixed effects models. The onset of breeding was characterised by the hatching date estimated on the basis of age characterised by the wing length of the oldest young when the nestlings of the brood were ringed. The size of owls was characterised by the wing length. The condition of parent birds before breeding was characterised by the body mass during breeding. The prey base of territories before breeding was characterised by the remains analysed from the nest bottom litter samples 
Table 4. Effects of Weather and Vole Abundance on Timing of Breeding in the Tawny Owl Strix aluco in Southern Finland Based on Linear Mixed Effects Models (Hatching Date Fixed Effects, Random Effects [Territory ID, Year]). Weather Variables Included Mean Winter Temperature, Snow Cover in March and Winter NAO Index. Vole Indices Included Water Vole Abundance (A) and Proportion (\%) in the Nest Bottom Litter Samples as well as Regional Small Vole Index in Spring. The Values of Effects, Standard Errors (SE), Degrees of Freedom (df), Test Statistics (t), Probabilities (p), Akaike's Information Criterions (AIC) and Numbers of Observations (N) Are Given. Negative Relationships Suggest Advancing Effects

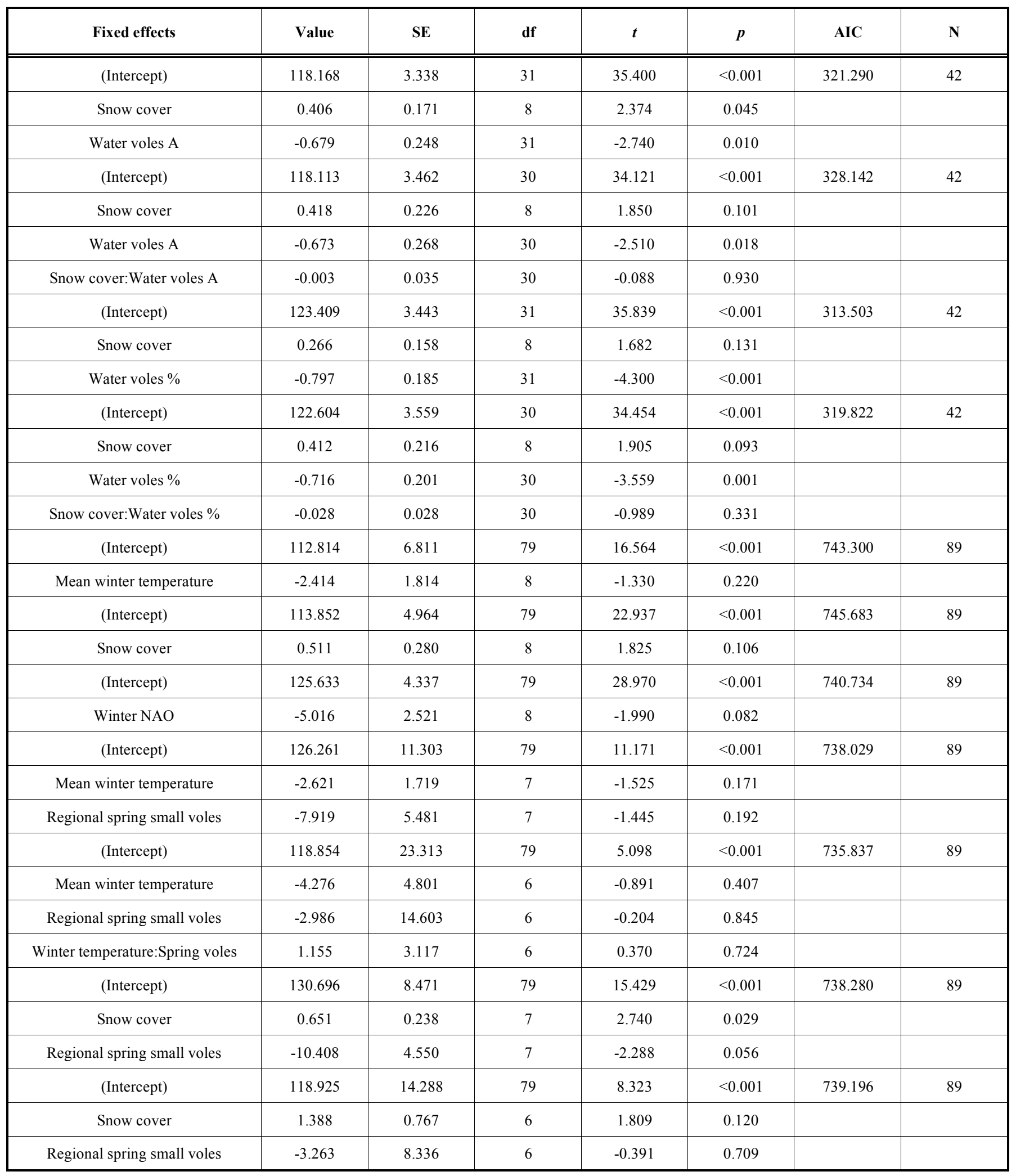


(Table 4) contd....

\begin{tabular}{|c|c|c|c|c|c|c|c|}
\hline Snow cover:Spring voles & -0.418 & 0.414 & 6 & -1.010 & 0.352 & & \\
\hline Winter NAO & -4.438 & 2.648 & 7 & -1.676 & 0.138 & & \\
\hline Regional spring small voles & -4.768 & 5.529 & 7 & -0.862 & 0.417 & & \\
\hline Regional spring small voles & -7.583 & 5.883 & 6 & -1.289 & 0.245 & & \\
\hline Winter NAO & -11.555 & 6.720 & 6 & -1.720 & 0.136 & & \\
\hline Winter NAO:Spring voles & 5.519 & 4.807 & 6 & 1.148 & 0.295 & & \\
\hline
\end{tabular}

Table 5. Effects of the Abundance of Small Voles on Timing of Breeding in the Tawny Owl Strix aluco on the Basis of Mixed Effects Models (Hatching Date Fixed Effects [Small Vole Abundance], Random Effects [Territory ID, Year]) with Various Local and Regional Vole Indices and Data Sets of Different Size. The 'Mean' Indices Are Averages Between Autumn and Spring. The Values of Effects, Standard Errors (SE), Degrees of Freedom (df), Test Statistics (t), Probabilities (p), Akaike's Information Criterions (AIC) as well as Numbers of Observations (N) and Years (Y) in Each Model Are Given

\begin{tabular}{|c|c|c|c|c|c|c|c|c|c|}
\hline Index/Data & Fixed effects & Value & SE & df & $t$ & $p$ & AIC & $\mathbf{N}$ & $\mathbf{Y}$ \\
\hline \multirow{2}{*}{ Territorial/small } & (Intercept) & 127.190 & 4.260 & 12 & 29.860 & $<0.001$ & 159.343 & 21 & 8 \\
\hline & Field voles in prey & -0.574 & 0.177 & 12 & -3.250 & 0.007 & & & \\
\hline \multirow{2}{*}{ Territorial/medium } & (Intercept) & 120.790 & 3.154 & 31 & 38.301 & $<0.001$ & 328.747 & 42 & 10 \\
\hline & Field voles in prey & -0.267 & 0.162 & 31 & -1.647 & 0.110 & & & \\
\hline \multirow{2}{*}{ Regional/small } & (Intercept) & 128.508 & 5.192 & 13 & 24.750 & $<0.001$ & 159.216 & 21 & 8 \\
\hline & Autumn field voles & -4.908 & 2.381 & 6 & -2.061 & 0.085 & & & \\
\hline \multirow{2}{*}{ Regional/large } & (Intercept) & 123.510 & 5.930 & 79 & 20.827 & $<0.001$ & 744.377 & 89 & 10 \\
\hline & Autumn field voles & -1.428 & 1.995 & 8 & -0.716 & 0.494 & & & \\
\hline \multirow{2}{*}{ Regional/small } & (Intercept) & 120.578 & 7.596 & 13 & 15.873 & $<0.001$ & 161.048 & 21 & 8 \\
\hline & Spring field voles & 0.596 & 6.394 & 6 & 0.093 & 0.929 & & & \\
\hline \multirow{2}{*}{ Regional/large } & (Intercept) & 119.648 & 6.538 & 79 & 18.301 & $<0.001$ & 742.787 & 89 & 10 \\
\hline & Spring field voles & 0.867 & 5.753 & 8 & 0.151 & 0.884 & & & \\
\hline \multirow{2}{*}{ Regional/large } & (Intercept) & 125.519 & 7.968 & 79 & 15.752 & $<0.001$ & 742.710 & 89 & 10 \\
\hline & Mean field voles & -3.346 & 4.492 & 8 & -0.745 & 0.478 & & & \\
\hline \multirow{2}{*}{ Territorial/small } & (Intercept) & 125.889 & 4.499 & 12 & 27.983 & $<0.001$ & 160.576 & 21 & 8 \\
\hline & Bank voles in prey & -1.606 & 0.703 & 12 & -2.283 & 0.041 & & & \\
\hline \multirow{2}{*}{ Regional/small } & (Intercept) & 125.585 & 8.841 & 13 & 14.204 & $<0.001$ & 163.473 & 21 & 8 \\
\hline & Autumn bank voles & 0.935 & 1.554 & 6 & -0.602 & 0.569 & & & \\
\hline \multirow{2}{*}{ Regional/large } & (Intercept) & 127.818 & 7.956 & 79 & 16.065 & $<0.001$ & 744.514 & 89 & 10 \\
\hline & Autumn bank voles & -1.434 & 1.338 & 8 & -1.072 & 0.315 & & & \\
\hline \multirow{2}{*}{ Regional/small } & (Intercept) & 128.056 & 7.626 & 13 & 16.792 & $<0.001$ & 159.618 & 21 & 8 \\
\hline & Spring bank voles & -7.492 & 6.631 & 6 & -1.130 & 0.302 & & & \\
\hline \multirow{2}{*}{ Regional/large } & (Intercept) & 128.263 & 6.387 & 79 & 20.082 & $<0.001$ & 740.462 & 89 & 10 \\
\hline & Spring bank voles & -8.890 & 5.871 & 8 & -1.514 & 0.168 & & & \\
\hline
\end{tabular}


(Table 5) contd....

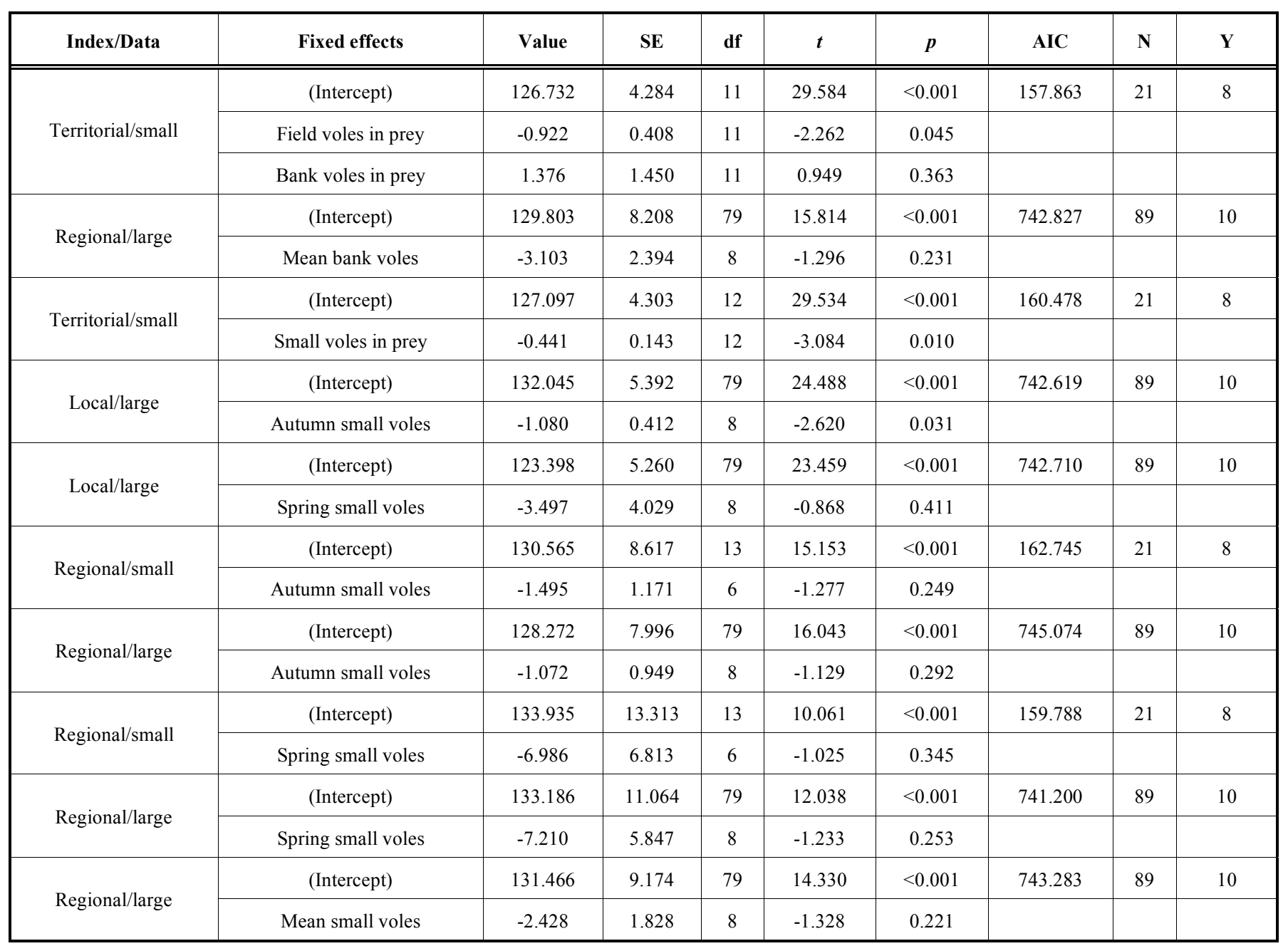

after breeding. Fluctuations in the general level of the food supply before breeding were described by the catch indices of local and regional snap-trappings in the preceding autumn or next spring. Climatic effects were depicted by single local or regional measures of the mean temperature of winter and the depth of the snow cover as well as the global winter indices of the North Atlantic oscillation.

Variation in the explanatory power of variables can be demonstrated by subsamples of larger data sets or by using corresponding data sets of different origin as replicates. In the present case, the samples were selected on the basis of the availability of required variables in each subsample. In addition, effects of vole abundance were examined based on the indices derived from sources of three spatial scales. Various differences emerged. Not surprisingly, in general, the local variables seemed to have a stronger association with the response variable than the regional ones. Larger samples from a data set did not always perform better than smaller ones, indicating that the real total variation in the variables concerned may be considerable.

Large differences emerged in the associations between subsamples of different size suggest that between territories there were also considerable differences other than those concerning the prey base and that were revealed by the re- mains in the nest bottom litter. These differences were sealed within the random effects in form of the territory IDs in the mixed effects models.

\section{The Best Models}

Several of the best models characterising the effects governing timing of breeding in tawny owls performed roughly equally with each other. This was probably due to the fact that the one and only significant factor, the occurrence of water voles, overwhelmingly governed the models and effectively outweighed the impact of other factors [cf. 9, 10]. Detailed ranking of the best models seems, however, not necessarily relevant or even reasonable if the proxies used poorly represent the variables intended. So, also the importance of the effects of single explanatory variables may be difficult to estimate [cf. e.g. 42]. Without an experimental approach, in such situations we can only state that there is or is not a significant association between the explanatory and response variables of the model.

\section{CONCLUSIONS}

Mixed effects models of a single fixed effect may give indications of importance of single variables. In models of two or more fixed effects, a governing factor, in the present 
Table 6. A Compilation of the Best Mixed Effects Models of the Associations of Characteristics of Parent Birds, Local Prey (Abundance [A] or Proportion [\%]), and Weather Conditions of the Preceding Winter with the Hatching Date of the Tawny Owl Strix aluco Clutches (Hatching Date $\sim$ Fixed Effects [Intrinsic Factors, Local Prey, Weather], Random Effects [Territory ID, Year]), Ranking Based on Akaike's Information Criterion (AIC). Also the Values of Effects, Standard Errors (SE), Degrees of Freedom (df), Test Statistics (t) and Probabilities (p) Are Given. In Each Model, the Number of Observations Is 21 and Number of Groups (Years) 8

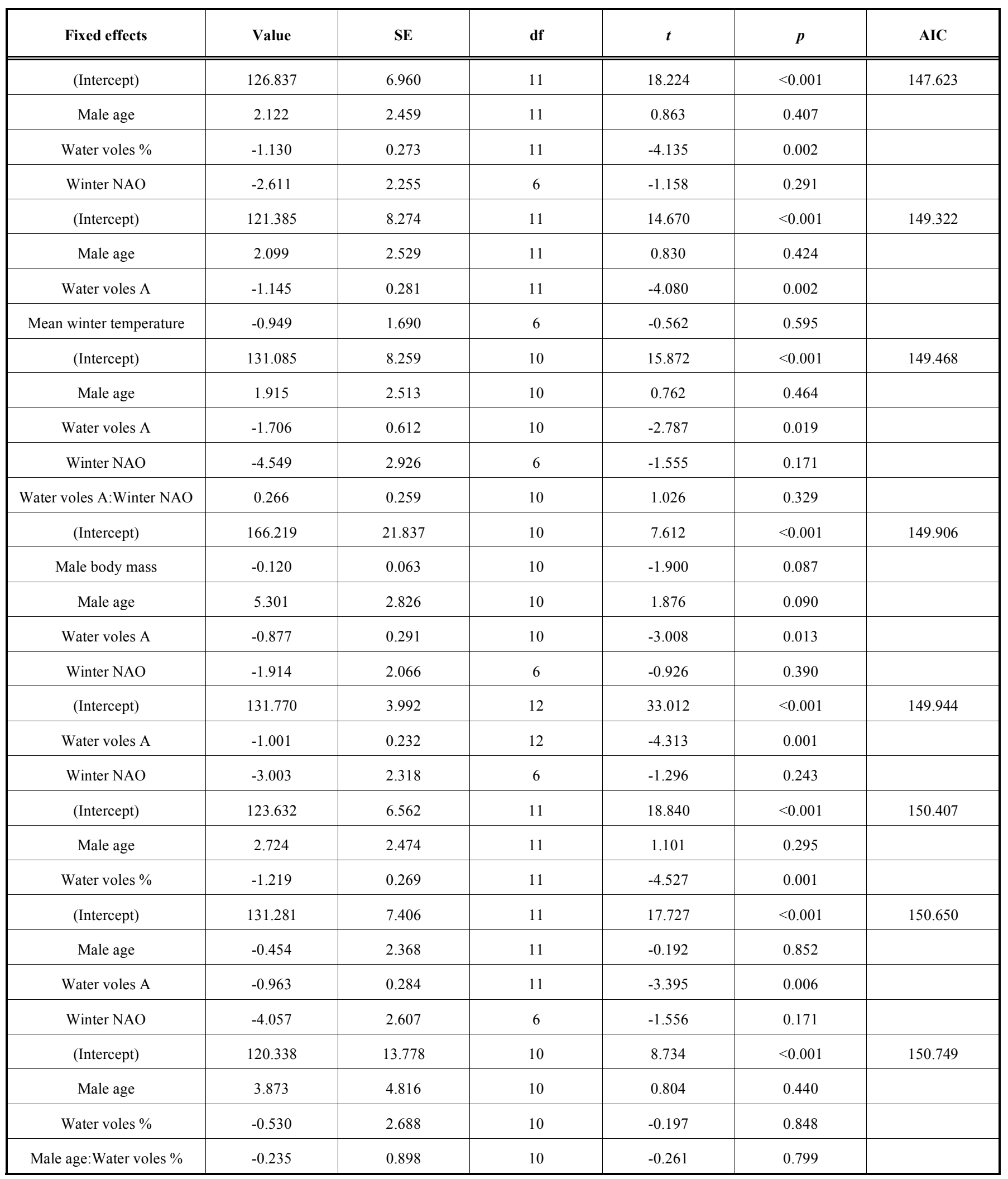


(Table 6) contd....

\begin{tabular}{|c|c|c|c|c|c|c|}
\hline (Intercept) & 130.232 & 8.206 & 9 & 15.870 & $<0.001$ & 151.486 \\
\hline Male age & -0.879 & 2.851 & 9 & -0.308 & 0.765 & \\
\hline Female age & 0.823 & 2.174 & 9 & 0.378 & 0.714 & \\
\hline Water voles A & -1.105 & 0.730 & 9 & -1.513 & 0.165 & \\
\hline Winter NAO & -3.907 & 2.726 & 6 & -1.433 & 0.202 & \\
\hline (Intercept) & 135.778 & 5.244 & 11 & 25.894 & $<0.001$ & 151.663 \\
\hline Water voles $\%$ & -1.625 & 0.601 & 11 & -2.701 & 0.021 & \\
\hline
\end{tabular}

case the prevalence of water voles, might outweigh the effects of some other variables. Though general regional or larger-scale indices may reveal associations between environmental factors and timing of breeding in owls, the most significant relationships can be found, as expected, as responses to relevant local and intrinsic factors. Present results suggest, that without detailed knowledge on the prey base of the territory, based only on the relatively easily available general small vole abundance indices, misleading results may emerge. The importance of small voles in governing breeding of owls may be overemphasized. However, prey samples from nests concern only the time period of breeding. Before breeding, particularly during winter, the availability of small voles may be of crucial importance for the breeding condition of parent birds and so it may have a decisive indirect effect on timing of breeding.

\section{CONFLICT OF INTEREST}

The author confirms that this article content has no conflicts of interest.

\section{ACKNOWLEDGEMENT}

Jari Pynnönen and Kimmo af Ursin made major contributions in the field work. Jonna Karhunen analysed the prey samples. Pentti Ahola and the Kimpari Bird Projects gave their vole trapping data at my disposal. The support of my family has been indispensable throughout the study. Nests were visited with permits from the Finnish Ministry of the Environment. Birds were handled according to accepted guidelines.

\section{REFERENCES}

[1] Perrins CM. The timing of birds' breeding seasons. Ibis 1970; 112: 242-55.

[2] Korpimäki E. Timing of breeding of Tengmalm's Owl Aegolius funereus in relation to vole dynamics in western Finland. Ibis 1987; 129: 58-68.

[3] Newton I. Population limitation in birds. London: Academic Press 1998.
[4] Dunn P. Breeding dates and reproductive performance. In: Møller AP, Fiedler W, Berthold P, Eds. Birds and climate change: advances in ecological research 35. London: Elsevier 2004; pp. 6987.

[5] Newton I. Population ecology of raptors. Berkhamsted: Poyser 1979.

[6] Pietiäinen H. Seasonal and individual variation in the production of offspring in the Ural owl Strix uralensis. J Anim Ecol 1989; 58: 905-20.

[7] Grandāns G, Keišs O, Avotinš A. Onset of breeding in Tawny Owl Strix aluco in eastern Latvia. Acta Univ Latviensis 2009; 753: 81-7.

[8] Solonen T, Karhunen J. Effects of variable feeding conditions on the Tawny Owl Strix aluco near the northern limit of its range. Ornis Fenn 2002; 79: 121-31.

[9] Solonen T. Factors affecting reproduction in the Tawny Owl Strix aluco in southern Finland. Ann Zool Fenn 2009; 46: 302-10.

[10] Kekkonen J, Kolunen H, Pietiäinen H, Karell P, Brommer JE. Tawny owl reproduction and offspring sex ratio in variable food conditions. J Ornithol 2008; 149: 59-66.

[11] Blūms P, Nichols JD, Hines JE, Lindberg MS, Mednis A. Individual quality, survival variation and patterns of phenotypic selection on body condition and timing of nesting in birds. Oecologia 2005; 143: 365-76.

[12] Verhulst S, Nilsson J-Å. The timing of birds' breeding seasons: a review of experiments that manipulated timing of breeding. Philos Trans R Soc B 2008; 363: 399-410.

[13] Downhower JF. Darwin's finches and the evolution of sexual dimorphism in body size. Nature 1976; 263: 558-63.

[14] Murphy MT. Body size and condition, timing of breeding, and aspects of egg production in eastern kingbirds. Auk 1986; 103: 465-76.

[15] Klomp H. Determination of clutch-size in birds: a review. Ardea 1970; 58: 1-124.

[16] Drent RH, Daan S. The prudent parent-energetic adjustments in avian breeding. Ardea 1980; 68: 225-52.

[17] Solonen T. Timing of breeding in rural and urban Tawny Owls Strix aluco in southern Finland: effects of vole abundance and winter weather. J Ornithol 2013; DOI 10.1007/s10336-013-0983-y

[18] Mikkola H. Owls of Europe. Calton: Poyser 1983.

[19] Cramp S, Ed. Handbook of the birds of Europe, the Middle East and North Africa. The birds of the Western Palearctic. Oxford: Oxford University Press 1985; Vol. IV.

[20] Southern HN. The natural control of a population of Tawny Owls (Strix aluco). J Zool 1970; 62: 197-285.

[21] Linkola P, Myllymäki A. Der Einfluss der Kleinsäugerfluktuationen auf das Brüten einiger kleinsäugerfressender Vögel im südlichen Häme, Mittelfinnland 1952-1966. Ornis Fenn 1969; 46: 45-78. 
[22] Solonen T. Are vole-eating owls affected by mild winters in southern Finland? Ornis Fenn 2004; 81: 65-74.

[23] Sundell J, Huitu O, Henttonen H, et al. Large-scale spatial dynamics of vole populations in Finland revealed by the breeding success of vole-eating avian predators. J Anim Ecol 2004; 73: 167-78.

[24] Solonen T. Reflections of winter season large-scale climatic phenomena and local weather conditions in abundance and breeding frequency of vole-eating birds of prey. In: Ulrich PK, Willett JH, Eds. Trends in ornithology research. New York: Nova Science Publishers 2010; 95-119.

[25] Petty SJ. Productivity and density of tawny owls Strix aluco in relation to the structure of a spruce forest in Britain. Ann Zool Fennici 1989; 26: 227-33.

[26] Solonen T, af Ursin K. Breeding of Tawny Owls Strix aluco in rural and urban habitats in southern Finland. Bird Study 2008; 55: 216-21.

[27] Solonen T. Breeding of the Tawny Owl Strix aluco in Finland: responses of a southern colonist to the highly variable environment of the North. Ornis Fenn 2005; 82: 97-106.

[28] Lehikoinen A, Ranta E, Pietiäinen $\mathrm{H}$, et al. The impact of climate and cyclic food abundance on the timing of breeding and brood size in four boreal owl species. Oecologia 2011; 165: 349-55.

[29] Spencer R. The Ringer's Manual. $2^{\text {nd }}$ ed. Oxford: BTO 1972.

[30] Jokinen M. Lehtopöllön poikasten kasvu ja energiankäyttö ja niiden vaikutus pesimätuloksen määräytymiseen. MSc thesis. Turku: University of Turku 1975.

[31] Sunde P, Bølstad MS, Møller JD. Reversed sexual dimorphism in tawny owls, Strix aluco, correlates with duty division in breeding effort. Oikos 2003; 101: 265-78.

[32] Petty SJ. A guide to age determination of Tawny Owl Strix aluco. In: Galbraicht CA, Taylor IR, Percival S, Eds. The ecology and conservation of European owls. Peterborough: Joint Nature Conservation Committee 1992; pp. 89-91.
[33] Schamber JL, Esler D, Flint PL. Evaluating the validity of using unverified indices of body condition. J Avian Biol 2009; 40: 49-56.

[34] Karhunen J. Lehtopöllön Strix aluco L. ravintobiologiasta EteläSuomessa. MSc thesis. Helsinki: University of Helsinki 2001.

[35] Solonen T, Ahola P. Intrinsic and extrinsic factors in the dynamics of local small-mammal populations. Can J Zool 2010; 88: 178-85.

[36] Hurrell JW, Kushnir Y, Visbeck M. The North Atlantic Oscillation. Science 2001; 291: 603-5.

[37] Osborn TJ. Simulating the winter North Atlantic Oscillation: the roles of internal variability and greenhouse gas forcing. Climate Dyn 2004; 22: 605-23.

[38] Pinheiro JC, Bates DM. Mixed-effects models in S and S-Plus. New York: Springer 2000.

[39] R Development Core Team. R: a language and environment for statistical computing. Vienna, Austria: R Foundation for Statistical Computing 2008. Available at: http://www.R-project.org

[40] Venables WN, Smith DM. The R Development Core Team: an introduction to R. Version 2.8.0. The R Project for Statistical Computing 2008. Available at: http://www.r-project.org

[41] Burnham K, Anderson D. Model selection and multimodel inference: a practical information-theoretic approach. $2^{\text {nd }}$ ed. New York: Springer 2002.

[42] Burnham KP, Anderson DR, Huyvaert KP. AIC model selection and multimodel inference in behavioral ecology: some background, observations, and comparisons. Behav Ecol Sociobiol 2011; 65: 2335 .

[43] Gladbach A, Gladbach DJ, Quillfeld P. Seasonal clutch size decline and individual variation in the timing of breeding are related to female body condition in a non-migratory species, the Upland Goose Chloephaga picta leucoptera. J Ornithol 2010; 151: 817-25.

[44] Hanski I, Henttonen H, Hansson L. Temporal variability and geographical pattern in the population-density of microtine rodents. $\mathrm{J}$ Anim Ecol 1994; 66: 353-67.

Received: October 04, 2013

Revised: October 26, 2013

Accepted: October 29, 2013

(C) Tapio Solonen; Licensee Bentham Open.

This is an open access article licensed under the terms of the Creative Commons Attribution Non-Commercial License (http://creativecommons.org/licenses/by-nc/3.0/) which permits unrestricted, non-commercial use, distribution and reproduction in any medium, provided the work is properly cited. 